\title{
26 Research Soure \\ Covid19 Response in Low-Income Country: The Case of A Lockdown in Zambia
}

Choolwe Mphanza Muzyamba ( $\nabla$ muzyamba@merit.unu.edu )

University College Utrecht

Research article

Keywords: Covid19, Lockdown, Zambia

Posted Date: August 12th, 2020

DOl: https://doi.org/10.21203/rs.3.rs-38257/v1

License: (c) (i) This work is licensed under a Creative Commons Attribution 4.0 International License.

Read Full License 


\section{Abstract}

Background The onset of the covid19 pandemic has sparked heated debate among scholars on the relevance of lockdowns. There are those in favor of the lockdown and others who are critical of it. However, despite the increased interest in understanding the relevance of lockdowns, there still has not been much focus on its relevance in low income countries like Zambia. Thus with the help of the SRT, we set out to explore and document the local characterization of the lockdown by residents of Lusaka, Zambia.

Methods A qualitative study in the form of interviews was conducted in Lusaka, Zambia involving a sample of 68 participants. Due to the lockdown measures that were in place during the study, the interviews were conducted via phone calls and the data collected were later analyzed by use of thematic analysis technique.

Results The lockdown was on one hand lauded for slowing down the incidence rates, preventing fatalities, and for protecting the healthcare system from collapse. On the other hand, it was criticized for exacerbating poverty levels, unemployment rates, increasing the rate of mental health problems, aiding gender based violence, and intensifying political repression and corruption. The results speak to the complexity in the characterization of the lockdown as a response to covid19 in Zambia. This observation demonstrates the folly of viewing, applying and characterizing the covid19 lockdown as a 'one-size-fitsall' approach in Zambia.

Conclusion Thus rather than definitely establishing the lockdown as an incontestable good, as it is depicted by some scholars or as useless by its critics, our findings instead demonstrate the diversity and complexity in how it is locally viewed by Zambians. The study provides grounds for caution on simplistic and binary characterization of lockdowns. It indicates the need for careful dialog between the designers of lockdowns and citizens in order to tailor such interventions to local realities in context-specific ways. It also shows that though the development of such interventions, all the various and complex elements it embodies must be taken into account in order to realize optimum outcomes.

\section{Background}

On March 2020, the World Health Organization (WHO) declared the coronavirus disease 2019 (COVID-19) a global health pandemic. COVID19 is a disease caused by a virus belonging to the large family of coronaviruses. Studies have indicated that the corona virus that causes COVID19 disease spreads from person to person through small respiratory droplets. COVID19 was first reported in Wuhan, in the Hubei province of China in December of 2019. Since then, the disease has spread worldwide. Various countries have responded differently to the threat of COVID19. The most common response (though to varying degrees) has been the concept of 'lockdown'. A lockdown is simply a government-issued emergency protocol that prevents people from leaving a given space [1]. Some governments around the world implemented full lockdowns while others implemented partial lockdowns. There has been several 
scholars in support of lockdowns in general. Prominent among them is Neil Ferguson and his team at Imperial college who demonstrated through mathematical models that in the UK alone, a lockdown would save over one hundred thousand lives $[2,3,4,5]$. These models were crucial in influencing a wave of lockdowns around the world. Other scholars pointed out that lockdowns enabled countries 'buy time' in order to get more familiar with the virus so as to guarantee appropriate responses [5]. The Lancet editorial team also argued that lockdowns were necessary to prevent a collapse of health care systems around the world [6]. Several other scholars expressed similar concerns by highlighting the dangers of increased numbers of new cases which were unmanageable given the limited number of bed-spaces, necessary medical equipment and staff in most hospitals around the world [7,5]. The other popular argument put forward by proponents of a lockdown was the need to 'flatten the curve'. This simply meant countering the exponential spread of the virus to keep the prevalence and death rates as low as possible until a possible cure or vaccine was discovered $[8,9]$

While lockdowns were embraced and implemented by most counties, the trend also attracted a plethora of critics. Lockdowns were criticized for relying on questionable projections which ended up delaying and worsening the Covid19 crisis as it prevented the development of herd immunity [11, 12]. Herd immunity occurs when a substantial proportion of the population develops protective antibodies after recovery from the disease. In the absence of a known cure or vaccine, some scholars contended that herd immunity seems like the most plausible alternative. However, given the prolonged lockdowns, thorough development of heard immunity was inhibited. Other scholars point out that lockdowns have less value in containing a virus that has already spread beyond control $[12,13]$. The argument here is that in a situation where the contagion and the actual number of infections are unknown, blindly locking down countries is merely a symbolic venture that does nothing to stop the spread [13]. Lockdowns have also been criticized for intensifying psychological and socioeconomic situations of citizens. Armitage and Nellums (2020) for example show that covid19-related lockdowns led to severe anxiety and depression, especially among the elderly [14]. This is because lockdowns curtail channels of constant social interaction thereby leading to feelings of loneliness and social isolation which are good breeding ground for anxiety and depression [14] Critics of lockdowns also believe that despite being well-intended, lockdowns could be producing more harm than good vis-à-vis the socioeconomic conditions of people, especially those living in low income countries $[15,16]$. Specifically, lockdowns are said to have led to high rates of job losses, businesses closures, slowed production process, reduced farming activities and distorted supply chains; all these disruptions are believed to negatively affect the economy and the consequences can be worse for marginalized people $[16,17,18]$.

While there is ample amount of research on relevance of lockdowns in responding to the Covid19 crisis in high income countries, such kind of studies are missing in low income countries like Zambia. More importantly, it is not yet known how people in such countries view and experience lockdowns. Hence this study aims to fill this gap by investigating the relevance of lockdowns as a tool for fighting covid19 by using Lusaka, Zambia as a case study. 
Zambia makes a good case study because it was one of the first low income countries in Sub-Saharan Africa to implement a country-wide lockdown. On the $13^{\text {th }}$ of March 2020, after recording 2 cases of Covid19, the president of the republic of Zambia Mr. Edgar Chagwa Lungu issued a statutory instrument number 22 of 2020 on Covid19. This statutory instrument outlined some of the measures and directives to help combat further spread of the disease. The measures included among others, a partial lockdown of the country in which schools, some shops, restaurants, entertainment activities, religious activities and other forms of social interaction were to be stopped with immediate effect. Citizens were ordered to stay at home as much as possible, and in order to help enforce these measures, police officers were deployed in the streets. Despite the implementation of these measures, it is still not known how citizens view and experience them. Understanding the various ways populations interpret and experience a given health intervention is key in ensuring program effectiveness as health interventions are most effective when they resonate with the worldviews and perceived interests of the people they are meant to serve [19]. Against this backdrop, this study explores the ways in which residents of Lusaka, Zambia characterize the relevance of the lockdown as tool for fighting covid19. Our aim is not to evaluate the impact of the lockdown, but rather to explore, examine and document these local understandings.

\section{Theoretical Framework}

The study is guided by the Social Representation Theory (SRT). The theory was developed by Serge Moscovici in 1961. It derives its roots from various fields including sociology, psychology and socialpsychology $[17,18]$. Its main purpose is to interrogate how social beliefs and realities evolve in society [19]. Primarily, this theory holds that any new phenomenon or health intervention derives its relevance through a process of assimilation, acceptance and appropriation among the constitutes of that society [9]. Specifically, when an intervention such as a lockdown is introduced, for it to be useful to the society, it must first be socially-acceptable to the people it is meant to serve. The people must first embrace it and afterwards, make efforts to assimilate and normalize it within that context. It has been shown that interventions that have local-buy-in are usually successful and sustainable. Conversely, if people fail to embrace the intervention, it is normally rejected and fails to produce its intended goals. Thus the social representation theory becomes a useful tool in explicating the relevance of new interventions from the perspectives of the people it is meant to serve. The tool thus helps to show in varying ways how society either accepts or rejects a new social phenomenon. $[13,14,15]$. Therefore, the theory of social representation in this study is used heuristically to help guide our investigation, interpretation and presentation of findings. The theory helps us understand in what ways the lockdown is relevant including its limitations in the fight against corona virus in Zambia from the perspective of the people it is meant to serve.

\section{Methods}

\section{Ethical clearance}


We obtained a written ethical clearance from the National Health Research Authority of Zambia (NHRAZ). We also ensured that participants were thoroughly informed of the objectives of the study and of their right to opt out of the study at any point should they feel the need to do so. After agreeing to participate, participants provided us with their written informed consent.

\section{Study site}

The study was conducted in Lusaka, Zambia, the political and economic capital of Zambia. At the time of the study, Lusaka had recorded the most cases of Covid19 [23]. Lusaka is also the most culturally, ethnically, and religiously diverse city in Zambia. These reasons made Lusaka the best case study as it allowed for relevance of the study and also enabled us to have a diverse set of participants in order to enrich our findings.

\section{Sampling}

We recruited our participants through convenient and purposive sampling techniques. This was done through the use of the ZAMTEL public phone records. Initial contact was made to potential participants and they were asked of their availability and willingness to participate in the interview. Upon agreeing to participate, they were included in the sample. A total of 68 people were selected to take part in this study. Their age ranged from 20 to 76 years old. 33 of them were male and 35 females. In the recruitment process, we also ensured diversity in terms of marital status, ethnicity, employment status, and religious affiliation. Our participants were drawn from various low, middle and income residential arears of Lusaka.

\section{Data collection}

All the data were collected using phone interviews. This was done with the help of 4 local research assistants. The research assistants were seasoned researchers; however, they also received additional training from the researcher responsible for this study in order to enable them conduct the research ethically and efficiently. The study took place from $13^{\text {th }}$ to $29^{\text {th }}$ of April 2020.

With the guidance of the SRT, we formulated 13 general questions covering issues regarding experience with the lockdown, opinions on its usefulness and limitations. We also asked follow-up questions to ensure thorough discussions (see interview guide). Each of the interviews took an average of 30 t0 40 minutes. Chinyanja the local language was used during the interviews and English were possible. The interviews were digitally recorded and then later translated and transcribed.

\section{Analysis}

During the analysis stage, we were guided by the social representation theory to conduct thematic analysis. Thematic analysis technique is a method of analysis that helps build and organize themes arising from the data. It works by systematically organizing, examining, summarizing and describing emerging themes arising from the data [10] . In this regard, similar opinions presented by our participants 
were logically clustered to form themes that gave meaning to the data. A summary of the results arising from this procedure are presented in table 1.

\section{Results}

Our participants highlighted the complex interplay of the usefulness of the lockdown as a response to the Covid19 pandemic. All in all, our results are divided into two broad categories, namely; positive and negative characterization of the lockdown.

On one hand, some participants expressed positive sentiments on the lockdown; they highlighted in many ways how useful the lockdown was. Specifically, the lockdown was credited for containing an impending health disaster. Participants were of the view that an unmitigated approach would have overwhelmed the healthcare system and caused more death.

"We can already see what is happening in European countries. Look at Italy. They having thousands people dying every day. Soon it will be us. We don't have a health care system that can handle the intensity of this virus, so I think the president did well to close down the country"

Participants were also concerned about the possibility of overwhelming the healthcare system in the country. They thus stated that the lockdown was useful in allowing government 'buy time' and ensuring that the already-struggling healthcare system was not overrun by several covid 19 cases. They viewed this as a necessary step to curb the number of deaths that could result both from covidq 9 itself and the lack of capacity to handle other illnesses.

"Do you think we have hospitals and ICU spaces to take in all the people who might need cares should they contract the virus? How prepared are we for this? Look, if they didn't lockdown deaths would have piling up because our hospitals are too weak to absorb all the health care needs that would result from high number of cases, and we would see more deaths"

Our participants also observed that given the uncertainties surrounding the novel virus, locking down seemed like the most logically-sound response. This action was both cautious and gave authorities time to learn more about how the virus behaved in order for them to design appropriate responses. They argued that it would have been careless to maintain the status quo given the potential consequences of such an action.

"Nobody knew how the virus will behave, everybody all over the world was locking down because of the uncertainties surrounding this virus. So to me it makes sense that the first thing you do is lock down than gamble with the lives of people"

While there were sentiments in support of the lockdown, some of our participants remained critical of it. They were concerned about its application and the consequences resulting from it. Particularly, some participants pointed out that the lockdown closed down possibilities of raising income for the most vulnerable. They stated that their lives were dependent on the daily errands which included various 
economic activities such as vending, hawking, and doing part-time jobs. All these avenues of raising income were closed down and without any corresponding government support, their economic situation became dire.

"I survive by vending, I sell tomatoes on the streets, that's how I raise money to feed myself and my kids. I don't have savings, this is how I survive. Look at me now, look how hungry we are. You think this is a logical thing to do? To starve us all out in the name of protecting the healthcare system?"

Not only that, others complained about the increasing threat of job losses because of the lockdown. Participants highlighted that several people within their circles were losing jobs at a rapid rate. This meant that most families were increasingly finding it difficult to meet their daily needs and poverty at household level was on the rise. They also pointed out that this trend was also detrimental to the government which losing ground to raise taxes necessary to maintain various social services functional in the country.

"companies are closing down and people are being let go. Unemployment is on the raise in the townships. People are struggling. Now, if companies are closing down, where will government find the money to fund health care, education, electricity? Where?"

The lockdown was also accused of contributing to the deterioration of mental health in the country owing to reduced human social interactions. Participants highlighted that Zambia societies were based on communal connections which people relied on for various forms of support. Cutting this off meant that people were left feeling isolated, stressed out and lonely.

"I have never felt like this before. I am not allowed to see my friends. I am not allowed to go to the bar and have a beer, talk about my problems to my friends. Ask for help where I can. I just feel so stressed locked down in this small space. These people are killing us with stress and loneliness."

Participants also complained of the increased number of gender-based violence and sexual assault in their circles. They stated that the lockdown had caused a disruption in normal day-to-day lifestyle activities in society and thus family members were meant to stick together more than usual. This had the potential of causing resentment towards each other thus leading to more women falling victims of violence at the hands of their male counterparts. Vulnerable children were also said to be at higher risk of sexual assault given the constant presence of male family members in close proximate.

"Now we are hearing more of violence against women in the neighborhood. We are getting reports of excessing violence towards women. Its in the news every day.... This is not good. Also, look at our young girls, you think they are safe in these homes with their uncles, cousins brothers. You know the stories. What is happening is really sad"

The lockdown was also seen as an excuse for government to increase its repression against citizens especially those with dissenting voices. The city of Lusaka was heavily militarized with security officers using excessive force on citizens who were deemed to have broken the lockdown rules. While the ruling 
party was allowed to have gatherings, other political parties and civil societies were met with excessive police brutality if the dared to do the same. Several other pronouncements were made to intimidate dissenting voices on the pretext of maintaining the lockdown rules. Minus any physical oversight from citizens owing to the lockdown, abuse of resources by officials was said to be rampart particularly resources donated to the fight against Covid19

"this is just an excuse for them to silence the opposition and loot our resources. Look at how they beat up and arrested those guys last Friday night. All this militarization of our neighborhoods, men with guns patrolling our neighborhoods, for what? We know these people are stealing all the donations for the covid fight. It is all over the news and people are not even allowed to ask questions"

Further, Zambia had recorded a significantly low number of deaths as compared to other countries. By end of April 2020, the covid-related death count stood at 4. As such, most participants felt the virulence in Zambia did not justify the lockdown. They pointed out that deaths from pandemics was not new in Zambia as the country had previously suffered various contentious pandemics, most of which claimed several thousands of lives in a short period of time but were managed without lockdowns. The consequences of the lockdown when weighed against the death rate at the time seemed counterproductive.

"In the last 3 months since Corona started making headlines, the country has only seen 4 deaths, only 4. Cholera kills more people and it is equally contentious. So given 4 deaths and compared to the damage the lockdown is causing, I really thing this action is somehow stupid. The lockdown is killing us, not the virus"

\section{Discussion}

The SRT helped illustrate various ways in which the lockdown has been characterized in Zambia. Broadly, the lockdown was understood in terms of its positive and negative consequences in the process of responding to the covid19 crisis.

There was evident support of the lockdown from our participants who argued that it was a necessary response to slow down the spread of the corona virus, prevent fatalities, and prevent the healthcare system from collapsing. Participants also suggested that failure to take any such measures against a novel virus whose actual infectiousness and virulence was not yet known amounted to recklessness. There has been similar support and sentiments from other parts of Africa $[2,3,4]$. The logic behind this position is based on the fact that Zambia's health care system has various shortcomings which can be seen from its consistent failure to effectively handle a plethora of illness such as malaria, malnutrition, diarrhea, cancer and HIV/AIDS [26, 27]. Therefore a further covid19-precipitated increase in patientnumber without any expansion in capacity of the healthcare system risks collapsing it. Covid19 patients require adequate human resource, availability of Personal Protective Equipment (PPE), ventilators and a constant supply of electricity, all of which were already in short-supply in Zambia [26]. There were several catastrophic predictions of deaths estimated in the range of one hundred to three hundred thousand in 
African countries like Zambia that still registered high HIV prevalence rates [28, 29]. It thus seemed careless to continue with the status quo. Our participants expressed little confidence in the healthcare systems' ability to handle an increased wave of covid19 cases. As such, a lockdown was seen as a cheaper, more effective and logical means of reducing this risk in the sense that it limits social contact and thereby cuts down on the infectiousness of the virus. Prevention of the virus through lookdowns rather than gambling with people's lives via a Laissez-faire approach seemed more logical.

While others saw the relevance of lockdowns, there was overwhelming criticism directed towards it. The lockdown was characterized as a disproportionate, out-of-touch and drastic response that ignored it's resulting consequences which were in most cases worse than the problem it aimed to solve. The lockdown was accused of closing down important economic avenues of survival among the most vulnerable in Zambia. A country in which the majority of the people are concentrated in informal economic activities such as street-vending, hawking and manual labor; lockdowns threatened their economic survival. Most families in Zambia survive on 'hand-to-mouth', usually luck savings and the ability to stock up. This means that closing down economic activities without any subsequent government subsidies worsens the already precarious poverty situations of many households. Our participants complained of the economic difficulties they had to endure at the hands of the lockdown whose purpose they did not fully grasp. Several scholars [30] have made similar observations in other African countries. Many of our participants viewed the threat of dying from poverty a more poignant reality than the lottery of contracting corona virus.

Other challenges such as increased mental distress, gender based violence and sexual violence against young girls at home were significantly pointed out. Mental health challenges especially for elderly people without possibilities of social interaction seemed to have been affecting many parts of Lusaka. Other studies have also shown similar trends in countries that have low income and high concentration of populations living in slums [31]. Further, riding on a culture that objectifies and victimizes women, lockdowns became convenient breeding ground for further abuse in Zambia. Participants highlighted their fear and concern on the continued threat of sexual and physical violence towards women in what they called 'caged-environments' which provided little opportunities of escape. Similar observations have been made elsewhere in countries like Kenya [32] where it was estimated that there was a significant rise in gender based violence in the country owing to lockdowns. Research has shown that lockdowns exacerbate pre-existing gender inequities, power-hierarchies, economic-stressors; as such, they contribute to increasing tension in households. This, coupled with the fact the women are constantly in closeproximate with their (potential) abusers, the frequency and severity of the abuse increases [32].

Our study also demonstrates how the lockdown was used as a convenient excuse for continued political repression, abuse of authority and corruption. Our participants made several observations of how freedoms of citizens especially those with dissenting views were constantly curtailed in the pretext of upholding the norms of the lockdown. The lockdown as suctioned through statutory instrument number 22 of 2020 took away citizens' ability to provide oversight on the government's conduct. The president and those in authority were accused of abusing their powers and further normalizing military-sanctioned 
violence on citizens. Similar reports of state-sanctioned violence on citizens in the name of upholding the lockdown have been reported in other African countries, particularly, Kenya, Uganda and South Africa.

Several researchers have raised concerns over the continued breakdown in the rule of law in most African countries hidden under the gaze of promoting public good though lockdowns. Some countries have already reported deaths of citizens at the hands of military personnel in the process of enforcing lockdown measures.

Our participants also questioned the justification of such a lockdown especially when weighed against the number of fatalities resulting from covid19. Many suggested that a lockdown (given its consequences) was a disproportionate response to a pandemic that had claimed only 4 lives in 3 months at the time. They also observed that pandemics in Zambia were not new. The key to Zambia's resilience against previous pandemics has been the use of mechanisms of response that carefully balanced risk of fatality and socioeconomic stability of the country; in the case of covid19, this seemed to have been ignored. As has been established in other low income countries, the psychological, socioeconomic, governance and political impact of a lockdown may be much greater than the risk posed by the corona virus itself $[7,18,32]$. Against the evidence of various negative consequences resulting from a lockdown, a plethora of scholars have concluded that in low income countries, it is a counterproductive and disproportionate response $[33,16]$.

Overall, our findings suggest a complex and multifaceted characterization of the lockdown. On one hand, it was seen as useful in slowing down the spread of the corona virus, preventing fatalities, and protecting the healthcare system from the risk of collapse. On the other hand, it compounded the predicaments of many households in various ways. It's negative consequences were especially observed in increased poverty levels, unemployment, cutting down lines of economic survival, high mental health problems, increased gender based violence, high rates of sexual violence, and intensified political repression and corruption. Thus rather than definitely establishing lockdown as an incontestable good, as it is depicted by some scholars $[28,11]$ or as useless by its critics $[7,19,34]$, our findings instead demonstrate the diversity and complexity in how it is locally viewed by Zambians.

\section{Limitations}

Due to various barriers such as funds, time and lockdown measures, we conducted our interviews by phone and were limited to Lusaka city alone. We were unable to conduct a country-wide study in order to have more representative responses. However, despite all that, our findings provide novel insights on how the corona-precipitate lockdown is characterized by the people it is meant to serve in low income countries like Zambia.

\section{Conclusion}

The onset of the covid19 pandemic has resulted in heated debates among scholars regarding the relevance of lockdowns as an intervention. It has gained supporters as well as critics. Despite the high interest in the efficacy of lockdowns, there is still a gap in literature regarding the realities of low income 
countries like Zambia. Thus with the help of the SRT, we set out to explore and document the local characterization of the lockdown by residents of Lusaka, Zambia. The SRT helped us unpack the various and complex ways the lockdown was viewed in Zambia. Specifically, it was established that the lockdown is on one hand lauded for slowing down covid19 incidence rates, preventing fatalities, and protecting the healthcare system from collapse. On the other hand, it is criticized for exacerbating poverty levels, unemployment rates, cutting down lines of economic survival, increasing the rate of mental health problems, aiding gender based violence, and intensifying political repression and corruption. These results speak to the complexity of a lockdown as a universal response to such pandemics. Thus the observation demonstrates the folly of viewing, applying and characterizing the covid19 lockdown as a 'one-size-fits-all' intervention in Zambia.

Much research remains to be done in order to generalize our findings to other low income countries. However, we argue that this study provides grounds for caution on simplistic and binary characterization of lockdowns. The study indicates the need for careful dialogue between the designers of lockdowns and citizens in order to tailor such interventions to local realities in context-specific ways. It also shows that though the development of such interventions, all the various and complex elements it embodies must be taken into account in order to realize optimum outcomes.

\section{Abbreviations}

COVID19: Coronavirus disease 2019

HIV: human immunodeficiency virus

PPE: Personal Protective Equipment

SSA: Sub-Saharan Africa

STR: Social Representation Theory

WHO: World Health Organization

\section{Declarations}

\section{Ethics approval and consent to participate}

We obtained written ethical clearance from the National Health Research Authority of Zambia. Other than that, during interviews, we collected written informed consent from the participants before participation, and at the same time, participants were made aware of their right to discontinue their participation from the study at any point should they wish to.

\section{Consent for publication}


Not applicable.

\section{Availability of data and materials}

The data generated and/or analyzed during the current study are not publicly available due to the fact that they contain people's private information but are available from the corresponding author on reasonable request.

\section{Competing interests}

The author declares no competing interests

\section{Funding}

The study was self-funded.

\section{Authors' contributions}

CM carried out all aspects of this study's design, analysis and interpretation, drafted the manuscript. Data acquisition was done with the help of 4 research assistants, The author read and approved the final manuscript.

\section{Acknowledgements}

We like to acknowledge the assistance by 4 research assistants

\section{References}

1. The-Economic-Times, "What a coronavirus lockdown looks likes, and what you can do \& what you can't," Economic Times, New York, 2020.

2. I. Dorigatti, L. Okell, A. Cori, N. Imai, M. Baguelin, S. Bhatia, A. Boonyasiri, P. Z. Cucunuba, G. CuomoDannenburg, R. Fitzjohn, H. Fu, K. Gaythorpe, A. Hamlet, W. Hinsley, N. Hong, M. Kwun, D. Laydon and N. Ferguson, "Report 1: Estimating the potential total number of novel Coronavirus cases in Wuhan City, China," Imperial College, London, 2020.

3. I. Dorigatti, L. Okell, A. Cori, N. Imai, M. Baguelin, S. Bhatia, A. Boonyasiri, P. Z. Cucunuba, G. CuomoDannenburg, R. Fitzjohn, H. Fu, K. Gaythorpe, A. Hamlet, W. Hinsley, N. Hong, M. Kwun, D. Laydon and N. Ferguson, "Report 2: Estimating the potential total number of novel Coronavirus cases in Wuhan City, China," Imperial colloge, London, 2020.

4. I. Dorigatti, L. Okell, A. Cori, N. Imai, M. Baguelin, S. Bhatia, A. Boonyasiri, P. Z. Cucunuba, G. CuomoDannenburg, R. Fitzjohn, H. Fu, K. Gaythorpe, A. Hamlet, W. Hinsley, N. Hong, M. Kwun, D. Laydon and N. Ferguson, "Severity of 2019-novel coronavirus (nCoV)," Imperial colloge, London, 2020.

5. N. M. Ferguson, D. Laydon, G. Nedjati-Gilani, N. Imai, K. Ainslie, M. Baguelin, S. Bhatia, A. Boonyasiri, Z. Cucunubá, G. Cuomo-Dannenburg, A. Dighe and Ilaria, "Report 9: Impact of non-pharmaceutical 
interventions (NPIs) to," Imperial College COVID-19 Response Team, London, 2020.

6. B. McCall, "Shut down and reboot-preparing to minimise infection in a post-COVID-19 era," The Lancent, 2020.

7. Editorial-The-Lancent, "India under COVID-19 lockdown," vol. 395, no. 10233.

8. R. M. Anderson, H. Heesterbeek, D. Klinkenberg and T. D. Hollingsworth, "How will country-based mitigation measures influence the course of the COVID-19 epidemic?," The Lancent, vol. 395, no. 10228, pp. 931-934, 2020.

9. J. Hellewell, S. Abbott, A. Gimma, N. I. Bosse, C. I. Jarvis, T. W. Russell, J. D. Muday and A. J. Kucharski, "Feasibility of controlling COVID-19 outbreaks by isolation of cases and contacts," Lancet Global Health, 2020.

10. M. Lipsitch, "Will COVID-19 go away on its own in warmer weather? Center for Communicable Disease Dynamics (CCDD) at the Harvard T.H. Chan School of Public Health.," Center for Communicable Disease Dynamics, Harvard T.H. Chan School of Public Health, Cambridge, 2020.

11. J. R. Hammond, "SARS-CoV-2 Response: Imperial College Model and Lockdown Endgame," Foreign policy journal, 2020.

12. J. Giesecke, "Lockdown-Free Sweden Had It Right, Says World Health Organization: Interview with Prof. Johan Giesecke," American institute for economic research, 2020.

13. Y. Xiao and M. E. Torok, "Taking the right measures to control COVID-19," The Lancent , 2020.

14. A. Park, "The Time for Containment Is Over. Welcome to the Next Phase of Coronavirus," New York, Time, 2020.

15. R. Armitagea and L. B. Nellumsa, "COVID-19 and the consequences of isolating the elderly," Lancet Public Health, 2020.

16. M. Choudhary, "Lockdowns: Towards a Nuanced View," BMJ, 2020.

17. F. Alvarez, D. Argente and F. Lippi, "A Simple Planning Problem for COVID-19 Lockdown," University of Chicago- working paper, 2020.

18. H. Inoue and Y. Todo, "Propagation of the economic impact of lockdowns through supply chains," VOX CEPR Policy Portal, 2020.

19. W. J. McKibbin and R. Fernando, "The Global Macroeconomic Impacts of Covid-19: Seven Scenarios," Crawford School of Public Policy, Australian National University, 2020.

20. C. Muzyamba, W. Groot, S. Tomini and M. Pavlova, "Community mobilization and maternal Care of Women Living with HIV in poor settings: the case of Mfuwe, Zambia," BMC Health Services, vol. 18, no. 155, 2018.

21. M. Bauer and G. Gaskell, "Social Representations Theory: A Progressive Research Programme for Social Psychology," Journal for the Theory of Social Behaviour, vol. 38, no. 4, pp. 1-19, 2008.

22. S. Moscovici, La psychanalyse, son image et son public, Paris: Presses Universitaires de France., 1961. 
23. S. Moscovici, "the history and actuality of social representations," In U. Flick (Ed) The psychology of the social. Cambridge: Cambridge University Press, 1998.

24. C. Muzyamba, E. Broaddus and C. Campbell, "You cannot eat rights": a qualitative study of views by Zambian HIV-vulnerable women, youth and MSM on human rights as public health tools," BMC International Health and Human Rights, vol. 15, no. 26, 2015.

25. Gardaworld-news, "Zambia: Country confirms first cases of COVID-19 March 18," Gardaworld-news, Lusaka, 2020.

26. B. M. Chitah, C. Chansa, O. Kaonga and N. W. Health, "Myriad of Health Care Financing Reforms in Zambia: Have the Poor Benefited?," Systems \& Reform, vol. 4, no. 4, pp. 313-323, 2018.

27. J. Phiri and J. E. Ataguba, "Inequalities in public health care delivery in Zambia," International Journal of Equity and Health, vol. 13, no. 24, 2014.

28. C. Anna, "Africa could see 300,000 coronavirus deaths this year, report says," Associated press, 2020.

29. WHO, "New WHO estimates: Up to 190000 people could die of COVID-19 in Africa if not controlled," Geneva, 2020.

30. D. Pilling, "In poor countries, the lockdown cure could be worse than disease," Financial times, 2020.

31. R. Burgess, "COVID-19 mental-health responses neglect social realities," Nature, 2020.

32. P. Keaveny, "Sexual and gender-based violence during COVID-19: lessons from Ebola," The conversation, 2020.

33. T. Bell, "Actuaries warn Ramaphosa of a 'humanitarian disaster to dwarf Covid-19' if restrictive lockdown is not lifted," Daily Marverick, 2020.

34. New-york-times, "Instead of Coronavirus, the Hunger Will Kill Us.' A Global Food Crisis Looms," New york, New york times.

\section{Supplementary Files}

This is a list of supplementary files associated with this preprint. Click to download.

- summaryofqualitativeresults.docx

- InterviewGuide.docx 